\title{
Traditional and Critical Mentoring
}

by Aaron Stoller

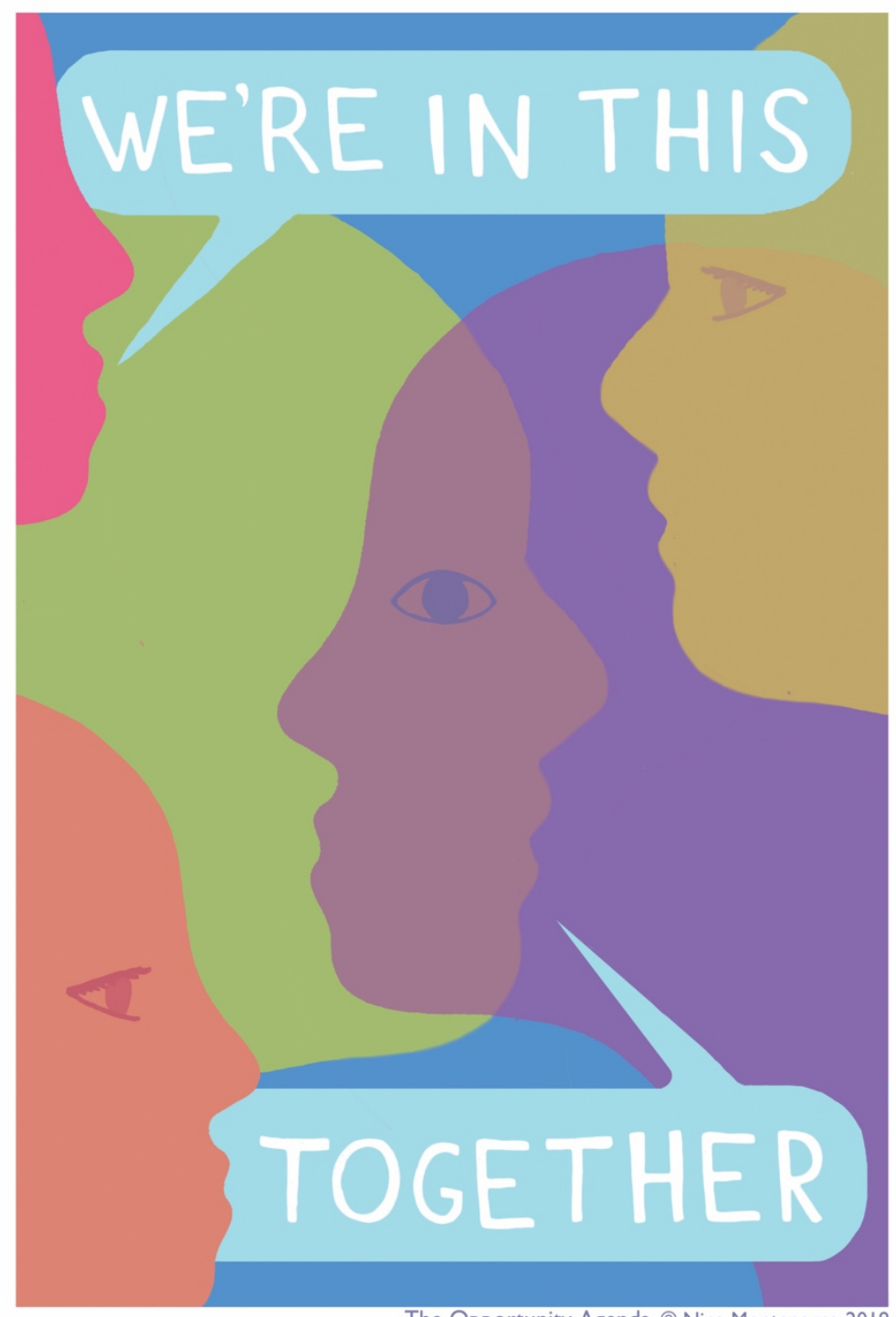

The Opportunity Agenda @ Nina Montenegro 2018

OPPORTUNITY AGENDA GRAPHICS, NINA MONTENEGRO (2019) VIA JUST SEEDS 
$\mathrm{T}$ he academy has long recognized that peer mentoring is an essential component of undergraduate learning and academic success. Almost all American colleges and universities have adopted some form of a formalized undergraduate peer mentoring program, which is usually centered on a site of student transition - for example, between high school and college, or as students enter a new program of study.

While undergraduate peer mentoring programs vary dramatically between campuses (Jacobi, 1991; Crisp \& Cruz, 2009), their overall frame of reference is almost always the same: they view mentoring as a process of assimilating students into the existing cultures, practices, and values of an institution or group. The unspoken assumption of these programs is that the more quickly newcomers adopt the attitudes, skills, and languages of the institution, as well as build positive networks within the institution, the more likely they will be to remain and succeed academically. Almost all of the literature on undergraduate peer mentoring follows suit, focusing on the development of various models, methods, or approaches for facilitating this process (e.g., Chan, 2008; Hill \& Reddy, 2007; Pitney \& Ehlerst, 2004), or describing the characteristics of peer mentors who might be effective facilitators of this process (e.g., Cramer \& PrenticeDunn, 2007; Terrion \& Leonard, 2007).

This article does not claim that traditional mentoring programs are ineffective in achieving their stated goals. There is a significant amount of evidence suggesting that these programs have a profound and positive effect on metrics such as student GPAs, retention rates, and graduation rates (Collings, Swanson, \& Watkins, 2014; Cutright \& Evans, 2016; Lane 2020). This article, instead, claims that traditional undergraduate peer mentoring programs are inadequate in achieving critical forms of education.

In the last twenty years, there has been a growing literature on critical mentorship (Margolis \& Romero, 2001). Although these models and theories go far in advancing critical forms of mentoring, they are generally focused on mentoring graduate students through doctoral programs (Humble, Solomon, Allen \& Blaisur, 2006), or mentoring new tenure-track faculty (Gair \& Mullins, 2001). When these literatures do address undergraduate students, they typically focus on the needs of specific marginalized and minoritized populations in the context of historically white colleges and universities (Smith, 2013; Weiston-Serdan, 2017). As a result, critical mentoring theory and practice have yet to meaningfully impact the general discourse of undergraduate peer mentoring at the university level (Crisp \& Cruz, 2009, p. 540). This essay is an attempt to bridge this gap.

It will begin with an overview of the four primary frameworks that ground traditional undergraduate peer mentoring programs in the US, which are broadly based on developmental theories. It will then present critical mentoring as an alternative theoretical framework, specifically focusing on how critical mentoring diverges in its conceptualization of the school and the student. Lastly, drawing on interviews with former critical mentors in my programs and my own lived experience, it will present a model of critical mentoring in practice. Ultimately, this essay will argue that undergraduate peer mentoring should not focus on assimilating students to an academic culture but should establish a dialogical and critical relationship between students and the environment in which their education will be enacted. It is only by establishing such a relationship that we might begin to cultivate critical intellectual agency in our undergraduate students.

\section{The Four Frameworks of Traditional Mentoring}

Almost all undergraduate peer mentoring programs in the United States are grounded in one of four general mentoring frameworks, which I call "traditional" mentoring programs (Smith, 2013, p. 56; Gershenfeld, 2014, p. 366).

\section{Mentoring as increasing involvement}

The first framework views mentoring as a process of increasing student involvement in a wide variety of academic activities, as early as possible in a student's college career. This framework draws from Alexander Astin's theory of student involvement (Astin, 1977, 1984, 1999). For Astin, student involvement refers to "the quantity and quality of the physical and psychological energy that students invest in the college experience" (Astin, 1999, p. 528). Involvement theory focuses exclusively on the behavioral mechanisms and processes that facilitate student development, as Astin argues that the extent to which students can achieve particular developmental goals is a direct function of the time and effort they devote to activities designed to produce these gains (Astin, 1999, p. 522). Astin's theory is focused on involvement in any form, such as absorption in academic work, participation in extracurricular activities, and interaction with faculty and other institutional personnel (Astin, 1999, p. 528). However, because there is broad recognition by most colleges and universities that student success is linked to academic performance, mentoring programs grounded in this framework typically encourage mentors to focus on encouraging mentees to get involved in a wide variety of traditional academic activities, such as increasing academic "time on task" activities like increased studying, as well as participation in undergraduate research opportunities (Smith, 2013, p. 56).

\section{Mentoring as facilitating integration}

A closely related framework views mentoring as a process of facilitating students' integration into the academic and social life of the campus. This framework is based primarily on Vincent Tinto's theory of academic and social integration (Tinto, 1975, 1982, 1993). Tinto argues that students are much more likely to persist and thrive if they are connected to the academic and social life of the institution, both within and outside the immediate context of the academic learning environment. By integration, Tinto means students' overall sense of belonging in campus culture, as evidenced by things like their willingness to participate in extracurricular activities, their overall feeling of involvement in and comfort with their academic 
experiences, and their general feeling of connectedness to other students and teachers (Severiens \& Schmidt, 2009). Tinto argues that individuals reformulate goals and commitments as a result of such integrative experiences and that positive experiences serve to reinforce institutional commitment. Mentoring programs of this type generally focus on creating positive academic and social experiences for undergraduate students as a means of helping them feel less alienated and building positive familiarity with the school environment. For instance, mentors may provide their mentees with opportunities to engage in informal socialization with faculty, staff, and other administrators so that they can build strong social networks (Smith, 2013, p. 56).

\section{Mentoring as providing support (and challenge)}

A third approach to mentoring views it as a process of offering students positive social support during the various challenges they face in the course of their education. This framework can be traced to psychologist Nevitt Sanford's studies of college students in the early 1960s (Sanford, $1962,1966)$. Stanford argues that optimal student growth requires that academic and challenges must be met with social-emotional supports so that students can sufficiently tolerate the stress of the challenge itself (Patton, Renn, Guido, \& Quaye, 2016). Challenges that students face can be motivated either internally or externally, and occur when the challenge upsets the current equilibrium of the student (Evans, Forney, Guido, \& Patton, 2010). The student may respond to a challenge in a variety of ways. If the challenge overwhelms the student, he or she may retreat and not grow from it. A reciprocal danger is that too much support is provided in relation to the challenge, in which case support results in stagnation in growth (Evans, Forney, Guido, \& Patton, 2010). Finding an adequate balance between providing challenges to and support for students is the key to this approach. Mentoring programs deploying this framework encourage mentors to meet with their mentees regularly to discuss concerns and provide support related to the student's entire college experience. For example, if a student has financial-aid issues, her mentor might call the Financial Aid office and make a personal request that the office schedule a meeting with the mentee (Smith, 2013, p. 57).

\section{Mentoring as role modeling}

A fourth framework for mentoring deliberately places various student developmental theories at the center of the mentoring relationship. There is a range of various developmental theories driving this approach to mentoring, such as Arthur Chickering's theory of identity development (Chickering, 1969), William Perry's theory of intellectual development (Perry, 1970/1999), or Lawrence Kohlberg's theory of moral development (Kohlberg, 1971). Mentoring programs of this type typically emphasize the mentor's awareness of the developmental stages of their mentees, rather than any specific behavior that might be engaged to move through those stages (Thomas, Murrell, \& Chickering, 1982). These programs also place a high emphasis on the selection of mentors who represent "advanced" developmental stages and can serve as role models for the kind of attitudes and behaviors desired of mentees (Smith, 2013, p. 57).

\section{Critical mentoring as an alternative paradigm}

Each of the four traditional mentoring frameworks intends to support students' agency through fostering a process of assimilation while, at the same time, activating developmental stages in students. The first three frameworks (i.e., involvement, integration, and support) are concerned with the behavioral mechanisms or processes that facilitate student development through student assimilation to culture, while the fourth (i.e., role modeling) emphasizes modeling developmental outcomes of the mentoring relationship (Astin, 1999, p. 522). There is no doubt that traditional mentoring frameworks provide a useful heuristic for guiding undergraduate mentoring practice. However, from a critical perspective, they also hold problematic core assumptions that not only undermine the very aims they intend to achieve but also commit unintentional acts of violence to the very students they intend to serve.

Traditional mentoring begins with the assumption that the school, as the site of student learning and growth, is either value-neutral or yields unilaterally positive impacts on students. In traditional approaches, the school is understood as little more than a container in which a generalized process of development is carried out.

Traditional mentoring's emphasis on "unlocking" inner developmental realms of the student has a long history in educational theory. It can be seen in Plato's theory of recollection, through Rousseau and his followers in educational theory, such as Kant and Pestalozzi. It moved into modern educational theory through early behaviorists like E.L. Thorndike. All of these theorists had a significant impact on the contemporary understanding of education, and all saw the process of learning as essentially a conflict between a human being's original (inner) nature and an (outer) social world (Russell, 1993, p. 176). This binary between person/environment remains rooted in traditional mentoring frameworks, rendering them incapable of accounting for the dynamic interrelatedness of history, culture, institutions, and the entanglements of persons and environments.

Critical mentoring, on the other hand, rejects the binary between person and environment, instead understanding persons as dialogically interrelated to and independent with the environments they inhabit. Critical approaches view learning as a socially situated process mediated through various environments, each with its own set of values, aims, cultures, and power relationships. Learning is a unique, context-bound process that takes place in and through all the environments a student inhabits (e.g., the classroom, dorm room, and athletics field).

Jean Lave and Etienne Wenger (1991), for example, argue that learning is a process of gaining increasingly 
legitimate "peripheral participation" inside communities of practice (p. 29). Learning is neither a process of valueneutral knowledge transmission (top-down) nor is it a process of passing through universal developmental stages (bottom-up). Instead, it is a culturally entangled process of developing modes of thinking and acting in live situations. At the same time, it is a process of increasing fluent inhabitation within communities where capacities and knowledge find their meaning and value (p. 53). Integration into a community of practice demands that members gain increasing fluency regarding the community's core values, can operate according to implied rules, and have the ability to engage in forms of practice (e.g., modes of writing, speaking, and thinking) specific to that community (Lave \& Wenger, 1991). This process also affects a deep, transformative change on the individual who increasingly becomes "a full participant, a member, a kind of person" (Lave \& Wenger, 1991, p. 53; emphasis added). What this means is that students, themselves, are social and cultural constructions that emerge from and are shaped by the environments they inhabit.

While there are undoubtedly positive effects of such socialization processes on student growth, critical mentoring also understands the process of learning as being mediated through patterns of domination and resistance between individuals and these environments. From a critical mentoring perspective, one of the most significant problems with traditional mentoring is that it evacuates the cultural politics of the institution and how those cultural politics shape the experience and identities of students. As a result, traditional mentoring fails to give students the tools to recognize the effects of this process of socialization on their emerging identities, nor are students given the critical tools necessary to engage the processes of socialization dialectically. Without holding such a critical awareness, learning and growth can easily slip from a form of empowerment into a process of alienation, marginalization, and colonization.

Critical mentoring begins from the perspective of the students who are being socialized by the school. It assumes neither that the needs of students align with the institution, nor that the processes of institutional socialization have a positive impact on students (Margolis \& Romero, 2001). Critical educational theory has a long history of identifying and analyzing the colonizing effects of schooling practices on the growth and identities of students. Although these critiques look at the effects of schooling from a variety of perspectives, such as race (Yosso, Smith, Cega, Solórzano, 2009), gender (Carlone \& Johnson, 2007), sexuality (Vaccaro, 2012), class (Taylor, 2008), etc..., what they share in common is an understanding that without attention to structures of power, domination, and resistance, schooling is largely a site of colonization that marginalizes and oppresses students. Critical mentoring is therefore aimed at fostering students' critical agency. Here, agency is understood as the capacity of a student to bring about selfdirected change and whose achievements are judged only in terms of the values and objectives set by the students themselves (rather than the goals the institution may have for him or her) (Sen, 1999). Working toward critical agency demands that a student develop the capacity to critically engage with (e.g., drawing from, resisting, reconstructing) the cultures, values, and practices of a school in the service of his or her self-articulated goals.

This goal of critical agency is built on the foundations of critical theory in that it takes human emancipation as its guiding interest. It also understands mentoring as a process of enabling students to meditate and respond to the intersection between their own lived experiences and the normative structures and cultures of the institution (Giroux, 1983). Critical agency demands that mentors empower and enable themselves and their mentees to take a dialectical (rather than monological or unidirectional) stance toward institutional culture.

Critical agency is grounded in Paulo Freire's notion of critical consciousness (1970/2000), a process in which people learn how to critically analyze their social conditions and act to change them (Watts, Diemer, \& Voight, 2011). Freire's model for critical consciousness rejects a universalized understanding of human development, such as those underpinning traditional mentoring programs. Instead, it understands growth as emerging out of the specific material and political contexts of individuals who work to conceptualize, critique, and reconstruct both their social roles and the overarching social order in which those roles are manifested. Traditionally, this process has been oriented toward the liberation of marginalized and minoritized populations because systems of domination impact these communities in specific and devastating ways. However, I understand critical consciousness as a wider concept that can be applied as a central conceptual tool within the context of mentoring. Taken in this wider sense, critical consciousness is a process by which any person works to disembed themselves from the norms, values, and expectations of their immediate cultural, social, and political environments via engaging in critical analysis and dialogue. It also requires those persons to take active efforts to reconstruct both their place in that environment and the environment itself (Mustakova-Possardt, 1998).

\section{Critical Mentoring in Practice}

In the previous section, I described how critical mentorship begins with the assumption that learning and growth are culturally and socially situated, and is mediated through patterns of domination and resistance between individuals and these environments. Further, the aim of critical mentorship is the cultivation of students' agency through a process of critical consciousness-raising leading to praxis. This section will build on the previous two by offering an account of critical mentoring practice grounded in my own experiences and the experiences of former mentors in my program.

\section{RADICALTEACHER}




\section{Background}

I have attempted to develop a framework for critical undergraduate peer mentoring over the last 13 years of working as a professional in institutions of higher education. This section describes how I put that framework into practice between 2011-2012 and 2015-2016 (five years) in a firstyear mentoring program in the context of a small, centralized University Honors Program (UHP) at a large, public land-grant research university situated in an urban context (University A). The university itself served approximately 26,000 undergraduate students of which 750 were students in the UHP. The UHP student body was broadly reflective of the institution as a whole: $55 \%$ male and $45 \%$ female; $67 \%$ White; $7 \%$ Asian; $6 \%$ Hispanic/Latino; $6 \%$ Black or African American; $4 \%$ International; $10 \%$ not reporting. The mentor program was made up of approximately 12 students annually, ranging from sophomores to seniors, who mentored approximately 200 incoming first-year UHP students. The majority of the first-year UHP students and all the mentors lived in the Honors Living-Learning Community (LLC).

During the first three years at University A, mentors worked with a "cluster" of mentees made up of a relatively equal number of incoming UHP students. The clusters were equally distributed based on core diversity metrics such as race, ethnicity, gender, and choice of major. Mentors were assigned randomly to these clusters. During this time, mentees lived in different areas of campus and were placed into different Honors first-year seminars. During the final two years at University $A$, each mentee cluster was designated by incoming UHP students' enrollment in a specific Honors first-year seminar. Mentors were assigned to each cluster/class through a collaborative process between my office and the faculty teaching first-year seminars. In addition to living in the LLC, mentors would attend these first-year seminars, often serving in a leadership role for the faculty member.

At University A, mentor training took place over three half-days scheduled before first-year students arriving oncampus. ${ }^{1}$ These three days were organized to move from the theoretical into the practical. Over the summer, mentors were required to read the first three chapters of Pedagogy of the Oppressed. The first day of training was focused on learning the core constructs of critical pedagogy through a combination of whole-group dialogue and individual reflection. The second day of training was focused on critical analysis through having mentors critically unpack their own educational identities and analyze the education environment of the university itself. To foster critical selfreflection on their identity, the mentors were asked to create a critical autobiography mapping their past educational experiences and then critically interrogating those experiences through the lens of race, class, gender, and sexuality. These autobiographies were shared in the group. As the facilitator, I also created and shared my critical autobiography. The second day also included a critical ethnography of physical space on campus. In this exercise, small groups of mentors chose a space on campus (e.g., the library, a classroom auditorium, the blueprint of campus itself) and analyzed it in terms of the way space was based on a particular set of beliefs about learning and student identities, as well as how space actively shaped the undergraduate students' process of learning and educational self-perception. The final day of training was focused on mentoring practice through learning techniques for interpersonal dialogue and community organizing. This third day of training was important because mentors in University A were not expected to organize traditional mentor "programs," but instead to view their role in terms of Freire's model for critical pedagogy: listening, dialogue, and action leading to praxis (see Figure 1).
Identify core beliefs (limit-situations)

- Mentor \& mentee as co-learner.

- Build relationships \& share experiences. 
dialogue circle. Mentors were then asked to engage, reflect on, and (as needed) adjust the plan as the year progressed. In addition to the individual plan for action, mentors were asked to keep a mentoring journal to reflect on their experiences and keep notes about general themes and patterns they noticed in their work with students. The dialogue circles were semi-structured and used as a time to reflect on the last two weeks, to share experiences, and to help generate ideas about how each mentor might move forward over the next two weeks.

\section{Reflections from Former Mentors}

In preparation for this article, I conducted semistructured interviews with 8 former mentors (out of $\sim 50$ total) who participated in various iterations of the mentoring program at University $A$. These interviews were transcribed and then thematic patterns were identified using a grounded theory approach. It is important to note that these findings represent a small, self-selected sample of former mentors who were invested enough in the experience to volunteer to be interviewed 3-7 years post-graduation. Despite this limitation, I believe that these themes support what I have witnessed from my own experience facilitating critical mentoring programs for the past 13 years.

1. Critical mentoring reframed the mentors' understanding of their educational process and gave them critical tools to empower themselves as students.

All the students interviewed expressed the idea that there was a shift that occurred during the experience as they came into contact with core ideas in critical pedagogy and began to recognize how they were socialized by the institution of schooling. Many of them expressed that gaining this understanding helped them beyond the mentor role, but was more broadly applicable in understanding themselves as a university student:

More than anything else, I think [the experience] helped to partially remove me "mentally" from the structure I was working in, including the very structure of being [a mentor]...I can equate it as a slightly less vivid version of studying abroad, which removes you entirely from what you're used to, and as a result, you can look back on what's familiar with a more critical and observant eye. After our reading sessions...it eventually gave me an invaluable perspective when it comes to being able to think on my own and operate within a predetermined structure without feeling as if I was held back by it.

I think being [a mentor] had more of an impact on me than on my mentees. In my opinion, I don't think I was very good at my job...I don't feel like I ever quite lived up to the dialogical expectations. Although, being a [mentor] helped to change my conception of education.

[What I realized is that] education influences who you are and how you instinctively interact with the world, not just the content of your thoughts.

2. Not all mentors in the program embraced the process or the theories
The idea that not all mentors embraced critical mentoring was mentioned by only one of the interviewees. However, I believe the comment is significant not only because the interview group self-selected specifically because they embraced the mentor role, but also because it is confirmed by my own experiences facilitating these programs. One interviewee commented:

...the number of [mentors] who actually cared about this was quite limited in my experience. Some [mentors] simply did not understand the task they were inheriting. I say this in all goodwill and harbor no contempt. Just an honest observation.

3. Those who embraced critical mentoring often struggled with the ideas in the context of the mentoring role.

In my interviews, this notion was expressed in two ways. First, almost all interviewees noted that as undergraduates they struggled with how to mediate the role without falling into cynicism about schooling:

The constant push to critically evaluate everything around us left me feeling very lost and uncertain. The perpetual, peer-pressured quest to identify what was wrong in everything around me left very little to cling onto as a way of finding some sort of truth and direction in the world.

I think that perhaps one of the inherent "dangers" of approaching mentorship from a critical perspective is that you are constantly critical (or at least questioning) of the system and of yourself, and this is multiplied exponentially in students who are possibly already more conscientious than your average [student].

Additionally, several mentors noted that the very act of taking a critical approach inserted a power dynamic between them and their mentees, even if they understood this was not the intention:

[Mentors] could very easily get caught up in the pedagogy and theory of critical thinking. At times, this, unfortunately, lead to a bit of a "superiority" complex amongst [mentors] (ironic because Pedagogy of the Oppressed is an antithesis to this very problem), so keeping things in perspective was incredibly important to make sure that students realized that in order for this method to be practical (and helpful), it had to be connected with everyday life and had to come from a position of collective learning.

The idea of rejecting the mentor role as a position of power was one I was very happy with, though I always wrestled with what I saw as some degree of tension between the rejection of the banking model of education and the idea that the [mentors] had access to a "correct" view of approaching the world in critical theory that we were supposed to get others to come around to. The process of teaching in the two models may be different, but the fundamental idea that the mentors are right-er and the mentees wrong-er was still there. 
4. Internalizing the theory took multiple years of working in the mentoring program, or happened only years after graduation.

Several mentors noted that they had re-read Pedagogy of the Oppressed after graduating and that it had begun to make more sense in the context of their professional lives. Two interviewees who were in the mentor role for several years as undergraduate students noted:

Reading Freire was significant in that way, then, though I don't know if I could say that I really got it at first. It took at least one more reading and several more years of being embedded in that environment and that peer group for those ideas to really sink in.

I almost felt like I "transformed" in my [mentor] journey - my first year was all about action orientation and figuring out how to be a mentor to my students, in my second year I was much more focused on the ideas behind why I was in this role, and in my third year I really felt like I was able to internalize them and was hopefully a better translator of these concepts, not only for the students in my cluster but also for myself.

5. The community of practice within the mentor group was highly significant in their growth.

Almost all mentors noted the community of practice within the mentor group was not only essential to them learning how to practice critical mentorship, but was highly significant to their growth. Most noted that the mentor learning community was far more significant than the work done with mentees:

If you do take as a starting position that the mentors are also in a process of development, then the environment [of] the mentor is one of the most important factors in determining how any program of critical mentoring is developed and sustained. ... [the] friendships I had with other current and former [mentors] was probably the biggest factor shaping the ideas I took in with me to the mentorship process.

6. The community of practice was a freeing space within an otherwise non-critical or instrumental schooling environment

This was an idea noted by several mentors, but it was expressed as both a positive and negative virtue of critical mentoring. Positively, many mentors expressed the idea that their community of practice was a space in which they felt free to discuss ideas and ask critical questions in a way that was different from other spaces on campus:

To engage in dialogue as an equal with an older mentor amid countless questions was to have the space to think critically and be forgiven...The space to test out unformed thoughts without judgment was a gift...

However, many also expressed that this critical orientation was simply not present in the rest of the university. This wider, non-critical environment shaped their expectations as they entered the role, often making it difficult to conceptualize what the program expected of them:

My model for education had been up to that point very transactional/didactical, where I would be the knowledgeable one, the explainer. If only I knew something well enough and had the right words, I could help somebody come to an understanding. This model had been reinforced by my experience as a teaching assistant/tutor in other parts of the university, the computer science, and physics departments.

It also impacted their ability to carry out the role with their mentees:

...it's just hard to critically mentor students when they are $90 \%$ of the time surrounded by what I might call "non-critical" classes across the university. ...I wholly accept that it's still possible to critically mentor a sincere student even if they are surrounded by bad educational influences across the university. But it's just harder to find those sincere students amidst all of the conflicting messages they get in other classrooms across campus. It's like fighting a tidal wave with a fist-sized rock. The rock works, but there is too much water. Someone has to really love and recognize the value of the rock for the rock to become useful.

It is important to note, as a facilitator of a critical mentoring program at both University A and, now, at a small, residential liberal arts college, this is a continued theme I hear from mentors. In my experience, the idea of the "noncriticality" of the university environment is not correlated to University A being a research institution but is generally descriptive in my experience of a basic lack of reflectivity present in most college and university environments, including liberal arts colleges.

\section{Although challenging, it was an experience that had a} positive impact on their learning and growth.

Several mentors noted this idea, but contextualized it by saying that it was impossible to differentiate what they learned "as a mentor" from other aspects of their undergraduate experience:

Something I strongly associate with my time [as a mentor] was the constant push not to take the world around me for granted, but criticize and question. I am cautious, though, to say how much of this was due to [the mentor experience] and how much was just [being] a young person in college...[The mentor program] certainly was different in that it attempted to give the criticism structure, but I think the most important factor is actually the peer group. It is more about being surrounded by other people who were pushing those same frames of criticism.

However, almost all noted that it was an overall positive experience that has had residual impacts on their thinking and lives:

I think the main thing that sticks is a certain attitude/approach/internal character change that shapes how I interpret and interact with in the world. 
I think a takeaway from my experience as a [mentor] and reading [Pedagogy of the Oppressed] is that the conversation is the fundamental unit of politics. In order to change people's beliefs you needed to develop a relationship with them.

To this day I still keep in touch with a few of my cluster, as friends...and being a [mentor] was one of the most defining experiences of my undergraduate career.

\section{Reflections from a mentor facilitator}

In addition to insights from former mentors, I would add the following four ideas based on my experience building and facilitating critical mentoring programs.

\section{Understand that critical mentoring is a complex learning experience for mentors}

Having led both traditional and critical programs, I have seen that although there is certainly learning and growth that occurs for mentors in traditional mentoring programs, it is of an entirely different kind than in a critical program. In traditional programs, expectations are clear, pathways to success are defined, and the labor is entirely practical. Critical programs, on the other hand, are not simply a form of practice but are a process of experiential learning for the mentors. Critical mentors are asked to confront their own identities and the system in which they work. They are also expected to become intellectually involved in their work in a way that is simply not present in a traditional program. This reality means that significantly more effort must be spent attending to their needs as learners throughout the process.

In my experience, there are always new mentors who expect to do the work of traditional mentoring and are frustrated by the ideas and expectations they find in a critical program. In these cases, I have found it important to allow them to make decisions about what kind of mentor they would like to become. For some, this means allowing them to leave the role with dignity if the expectations become too overwhelming. For others, it means developing a plan of work that creates a bridge between critical practice and their values.

Another (more frequent) learning challenge is mentors who are emboldened by the ideas, but who struggle translating those ideas to practice. In my experience and as evidenced in the interviews this leads to three different kinds of challenges: (a) mentors often incorrectly translate the framework into a kind of superiority complex, (b) they become paralyzed by a critical stance, or (c) they become overwhelmed by what they perceive as a lack of immediate impact of their work. Consistent reflection and the use of dialogue circles are essential to addressing all of these needs. In my experience, dialogue circles helped deepen mutual understanding and, more significantly, gave me - as a facilitator - an opportunity to identify, assess, and intervene when mentors were struggling. The dialogue circles also allowed me to continually remind them that selfreflection and time away from the position is a legitimate form of critical practice. More recently, I have moved to a model where all mentors are required to take a 1-credit practicum course which is organized in the same way as dialogue circles. The credit-bearing model allows us to dive deeper into the root causes and potential pathways for action on the issues they see in their mentee groups.

\section{Treat critical mentoring as a legitimate form of} intellectual labor

The credit-bearing practicum model also addresses another challenge, which is getting the mentors to conceptualize and embrace this work as a legitimate form of intellectual labor. Since students are socialized into the traditional schooling paradigm of "academic" vs "nonacademic," it was difficult in the early days to get new mentors to read or legitimately engage with critical theory outside a traditional classroom context. It was equally difficult to get them to meaningfully reflect on their experience through journaling (which is an expectation for all mentors). Most entering mentors simply view "thinking" as an activity strictly for the classroom and "doing" (e.g., organizing events, advertising opportunities, formal meetings) as the primary activity of a job. As such, many new mentors did not embrace the role as a form of intellectual labor.

Placing the mentoring program in the context of a practicum course blurred the boundaries between the "academic" and "non-academic," and helped give a framework for mentors to understand that activities such as reading, reflection, and dialogue were included as a legitimate form of work within mentoring practice. It also helped mentors understand why they should invest thoughtfully in the construction of a mentoring plan. As previously mentioned, critical pedagogy is not a method but a process. As such, mentors are required to construct their own grounded methods of practice in conversation with their dialogue circle. Through the years, this expectation has frustrated many mentors who prefer a methodological template (i.e., programming model) to be provided to them so they can easily complete the "tasks" required of them in the role. In requiring them (with the support of a dialogue circle) to create a mentoring plan, they are forced to ask critical questions and take intellectual ownership over their mentoring practice. Outside of a classroom context, this was often frustrating or overwhelming for mentors.

\section{Calibrate expectations carefully and appropriately}

Mentors who embrace the role often struggle with understanding its norms and expectations. On the one hand, some students find it difficult to "know" if they are doing enough in the role absent traditional markers (i.e., numbers of programs produced or student contact hours). On the other hand, there are students whose expectations for impact are far too lofty and believe that their goal is to revolutionize the institution of schooling overnight. In both cases, it is important to develop a communal understanding of "success" in the position.

I typically hold an initial workshop on "defining success" in the context of late summer training in which we collectively map our ideas of success and connect those 
ideas to particular impacts. The facilitator must be heavily involved in this process to norm expectations appropriately. I then ask all mentors to include a section on "successful" mentoring in the context of their mentoring plan, which we review periodically in mentoring dialogue circles.

For mentors who struggle with what they view as a lack of clear guidelines, this process helps them feel confident they are making progress toward a goal. It also opens the door to allow a discussion regarding why activities that don't "feel" like work (e.g., spending time in reading, reflection, and dialogue with mentees) are legitimate forms of activity that contribute to their overall success. For mentors who overestimate what is possible in the role, this exercise also helps ground their enthusiasm in smaller, more achievable steps. For example, rather than having critical consciousness as a goal of their mentoring activity, I will often redirect them in the first semester to simply focus on relationship building. This can be demonstrated, for example, by mentors being able to reflect on meaningful conversations they've had with their mentees, and articulate critical questions they want to ask them in future conversations.

\section{Take seriously the challenge critical mentoring presents to institutional paradigms.}

Like other forms of critical pedagogy, critical mentoring is empowering because it challenges traditional ways of being and behaving. It is therefore highly important that mentor program facilitators recognize and take seriously the inherent dangers in this process. Throughout the years, I have worked with mentors who have gone beyond dialogue to critical action leading to activities like organized protests, sit-ins, and campaigns (both on- and off-campus). In all of these cases, the mentor facilitator must be aware of these emerging activities, help the mentors and mentees contextualize their ideas, imagine possibilities for action, and identify potential consequences of those actions.

Additionally, this work - like all critical work - means that the mentor facilitator can quickly become the object of criticism from other faculty, staff, and administrators. These criticisms can be limited and local, or can become more serious. It is important that, like the mentors themselves, facilitators understand their positionalities and limits. In my work, I have been repeatedly criticized by staff and assessment professionals for facilitating a program that is not easily quantifiable and does not map onto pre-defined learning goals. I have also been criticized by upper administration for "encouraging" students to engage in behaviors that do not reflect well on the institution's brand.

I have been most frequently criticized, however, by faculty. These criticisms are typically motivated because this work - like all critical pedagogies - problematizes traditional faculty authority. On one hand, there are those faculty who oppose it because it often leads to students (both mentors and mentees) questioning the built environment of the classroom learning environment. On the other hand, there are those faculty who oppose it because they believe it undermines the formal curriculum and classroom being the seat of student learning. For example, after I explained the aims and scope of my critical mentoring program to a curious faculty member, I received the following email:

This looks to me like encasing students in a cocoon which circumvents self-discovery...and it promotes the administrative structure over the academic. This is social engineering at the expense of the life of the mind.

Here, the faculty member expresses the idea that "the mind" is the exclusive domain of traditional faculty members and any form of practice that challenges or questions this idea is a form of "social engineering." It is therefore important that the mentor facilitator understand they are also embedded in the work and that this positionality comes with particular dangers.

\section{Conclusion}

In this essay, I have sought to advance a critical basis for undergraduate peer mentoring, which diverges from the traditional frameworks guiding most undergraduate peer mentoring programs in the US.

While there is no doubt that traditional mentoring frameworks have provided useful frameworks for supporting students' transition to and integration in colleges, they have failed to account for the potential negative effects of mentoring and the wider socialization processes on mentees. Implicit in traditional mentoring models is the idea that the socialization process is not only positive but also more "successful" for those aligned with the values of the institution. The goal of mentoring is assimilation or, for those who are misaligned with institutional values, to code-switch as a way of becoming more institutionally accepted and acceptable. Left out of these discussions is the acknowledgment that such processes have a colonizing effect on the identities of students who are expected to submit to a distinct cultural consciousness (often rooted in normative class, race, and gender assumptions) to become legitimate participants (Gair \& Mullins, 2001, pp. 35-36).

Critical mentoring, on the other hand, is a process of naming, critically analyzing, and resisting the invisible forces of domination that shape students' experiences and emerging identities. From a critical standpoint, undergraduate mentoring is an intervention: it is a way of provoking critical engagement with culture. In doing so, mentorship becomes a practice of critical empowerment that enables students to recognize their capacities and values in dialectical relationship to the institution in the pursuit of critical agency.

\section{Notes}

${ }^{1}$ At University A, I was not successful in implementing a required, semester-long mentoring class, but I did teach a spring Honors course in critical pedagogies that became an informal training opportunity for aspiring mentors. It was quickly apparent that the students who took this class were more prepared for the critical mentoring role. I have since developed this class into a critical mentoring practicum that meets once per week throughout the Fall semester and is required for all mentors (new and returning) in my current 
program. The course blends core reading with practical reflection.

\section{Works Cited}

Astin, A. (1977). Four critical years: Effects of college on beliefs, attitudes and knowledge. San Francisco, CA: Jossey-Bass.

Astin, A. (1984). Student involvement: A developmental theory for higher education. Journal of College Student Personnel 25, 287-300.

Astin, A. W. (1999). Student involvement: A developmental theory for higher education. Journal of College Student Development, 40(5), 518-29.

Au, W. (2007). Epistemology of the oppressed: The dialectics of Paulo Freire's theory of knowledge. Journal for Critical Education Policy Studies, 5(2), 1-18.

Bartolome, L. (1996). Beyond the Methods Fetish: Toward a Humanizing Pedagogy. In: P. Leistyna, A. Woodrum, and S. Sherblom (Eds.), Breaking free: The Transformative Power of Critical Pedagogy. pp. 229252. Harvard Educational Review.

Bronner, S.E. (1994). Of critical theory and its theorists. Oxford: Blackwells.

Carlone, H. B., \& Johnson, A. (2007). Understanding the science experiences of successful women of color: Science identity as an analytic lens. Journal of Research in Science Teaching, 44(8), 1187-1218.

Chan, A. W. (2008). Mentoring ethnic minority, pre-doctoral students: An analysis of key mentor practices. Mentoring \& Tutoring: Partnership in Learning, 16(3), 263-277.

Chickering, A. (1969). Education and identity. Jossey-Bass.

Collings, R., Swanson, V., \& Watkins, R. (2014). The impact of peer mentoring on levels of student wellbeing, integration and retention: a controlled comparative evaluation of residential students in UK higher education. Higher Education, 68(6), 927-942.

Cramer, R., \& Dunn, S. (2007). Caring for the whole person: Guidelines for advancing undergraduate mentorship. College Student Journal, 4, 771-778.

Crisp, G., \& Cruz, I. (2009). Mentoring college students: A critical review of the literature between 1990 and 2007. Research in higher education, 50(6), 525-545.

Cutright, T. J., \& Evans, E. (2016). Year-long peer mentoring activity to enhance the retention of freshmen STEM students in a NSF scholarship program. Mentoring \& Tutoring: Partnership in Learning, 24(3), 201-212.

Degener, S. C. (2001). Making sense of critical pedagogy in adult literacy education. Annual review of adult learning and literacy, 2(1), 26-62.
Evans, N. J., Forney, D. S., Guido, F. M., Patton, L. D., \& Renn, K. A. (2010). Student development in college: Theory, research, and practice (2nd Ed.). San Francisco, CA: Jossey-Bass.

Freire, P., Fraser, J. W., Macedo, D., McKinnon, T., \& Stokes, W. (Eds.). (1997). Mentoring the mentor: A critical dialogue with Paulo Freire. New York, NY: Peter Lang.

Freire, P. (2000). Pedagogy of the oppressed. New York, NY: Continuum. (Original work published in 1970.

Gair, M., \& Mullins, G. (2001). Hiding in plain sight. In the image and likeness: How mentoring functions in the hidden curriculum. In E. Margolis (Eds.) The hidden curriculum in higher education (pp. 21-41). New York, NY: Routledge.

Gershenfeld, S. (2014). A review of undergraduate mentoring programs. Review of Educational Research, 84(3), 365-391

Giroux, H. (1983). Theory and resistance in education: Towards a pedagogy for the opposition. Westport, CT: Bergin \& Garvey

Habermas, J. (1980). Psychic thermidor and the rebirth of rebellious subjectivity. Berkeley Journal of sociology, 24, 1-12.

Haring, M. J. (1999). The case for a conceptual base for minority mentoring programs. Peabody Journal of Education, 74(2), 5-14.

Held, D. (1980). Introduction to Critical Theory: Horkheimer to Habermas. University of California Press.

Hill, R., \& Reddy, P. (2007). Undergraduate peer mentoring: An investigation into processes, activities and outcomes. Psychology Learning and Teaching, 2, 98103.

Humble, A. M., Solomon, C. R., Allen, K. R., \& Blaisur, K. R. (2006). Feminism and mentoring of graduate students. Family Relations, 55(1), 2-15.

Jacobi, M. (1991). Mentoring and undergraduate academic success: A literature review. Review of educational research, 61(4), 505-532.

Kohlberg, L. (1971). Stages of moral development. In C. M. Beck, B. S. Crittenden, \& E. V. Sullivan (Eds.), Moral education. Toronto: University of Toronto Press.

Lane, S. R. (2020). Addressing the stressful first year in college: Could peer mentoring be a critical strategy? Journal of College Student Retention: Research, Theory \& Practice, 22(3), 481-496.

Lave, J. \& Wenger, E. (1991). Situated learning: Legitimate peripheral participation. New York, NY: Cambridge UP.

Liou, D. D., Martinez, A. N., \& Rotheram-Fuller, E. (2016). "Don't give up on me": critical mentoring pedagogy for the classroom building students' community cultural 
wealth. International Journal of Qualitative Studies in Education, 29(1), 104-129.

Margolis, E., \& Romero, M. (2001). In the image and likeness: How mentoring functions in the hidden curriculum. In E. Margolis (Eds.) The hidden curriculum in higher education (pp. 79-97). New York, NY: Routledge.

McDaugall, M., \& Beattie, R. S. (1997). Peer mentoring at work: The nature and outcomes of non-hierarchical developmental relationships. Management learning, 28(4), 423-437.

McGuire, G. M., \& Reger, J. (2003). Feminist co-mentoring: A model for academic professional development. NWSA journal, 54-72.

Morrow, R., \& Brown, D.D. (1994). Critical theory and methodology. Thousand Oaks, CA: Sage.

Mustakova-Possardt, E. (1998). Critical consciousness: An alternative pathway for positive personal and social development. Journal of Adult Development, 5(1), 1330.

Patton. L. D., Renn. K. A., Guido. F. M., \& Quaye S. J. (2016). Student Development in College: Theory, Research, and Practice Third Edition. San Francisco, CA: Jossey-Bass. pp. 12-36

Perry, W. G. (1999). Forms of ethical and intellectual development in the college years: A scheme. San Francisco: Jossey-Bass. (Original work published 1970).

Pitney, W., \& Ehlers, G. (2004). A grounded theory study of the mentoring process involved with undergraduate athletic training students. Journal of Athletic Training, 4, 344-351.

Russell, D. R. (1993). Vygotsky, Dewey, and externalism: Beyond the student/discipline dichotomy. Journal of Advanced Composition, 173-197.

Sanford, N. (1962). The American college. New York: Wiley.

Sanford, N. (1966). Self and society: Social change and individual development. New York: Atherton

Severiens, S. E., \& Schmidt, H. G. (2009). Academic and social integration and study progress in problem based learning. Higher Education, 58(1), 59.

Sen, A. (1999). Development as freedom. New York, NY: Anchor Books.

Smith, B. (2013). Mentoring at-risk students through the hidden curriculum of higher education. Lexington Books.

Taylor, Y. (2008). Good students, bad pupils: Constructions of "aspiration", "disadvantage" and social class in undergraduate-led widening participation work. Educational Review, 60(2), 155-168.
Terrion, J., \& Leonard, D. (2007). A taxonomy of the characteristics of student peer mentors in higher education: Findings from a literature review. Mentoring \& Tutoring: Partnership in Learning, 15, 149-164.

Thomas, R., Murrell, P. H., \& Chickering, A. W. (1982). Theoretical bases and feasibility issues for mentoring and developmental transcripts. New directions for student services, 1982(19), 49-65.

Tinto, V. (1975). Dropout From Higher Education: A Theoretical Synthesis of Recent Research. Review of Educational Research, 45, 89-125.

Tinto, V. (1982). Defining Dropout: A Matter of Perspective, In Pascarella, E.T. (Eds.), Studying Student Attrition. San Francisco: Jossey-Bass, 3-15.

Tinto, V. (1993). Leaving College: Rethinking the Causes and Cures of Student Attrition, 2nd(ed.), Chicago: University of Chicago Press.

Vaccaro, A. (2012). Campus microclimates for LGBT faculty, staff, and students: An exploration of the intersections of social identity and campus roles. Journal of Student Affairs Research and Practice, 49(4), 429-446.

Watts, R. J., Diemer, M. A., \& Voight, A. M. (2011). Critical consciousness: Current status and future directions. New Directions for Child and Adolescent Development, $134,43-57$.

Weiston-Serdan, T. (2017). Critical mentoring: A practical guide. Virginia: Stylus Publishing

Yosso, T., Smith, W., Ceja, M., \& Solórzano, D. (2009). Critical race theory, racial microaggressions, and campus racial climate for Latina/o undergraduates. Harvard Educational Review, 79(4), 659-691. (cc) EY-NG-ND

ULLS D-Sorle
This work is licensed under a Creative Commons Attribution-Noncommercial-No Derivative Works 3.0 United States License.

This journal is published by the University Library System of the University of Pittsburgh as part of its D-Scribe Digital Publishing Program, and is cosponsored by the University of Pittsburgh Press.
RADICALTEACHER 